(2) Open Access Full Text Article

ORIGINALRESEARCH

\title{
Implementation of Blended Learning Approach for Improving Anatomy Lectures of Phase I MBBS Students - Learner Satisfaction Survey
}

\section{Suchismita Sarkar (D) \\ Saroj Sharma \\ Shashi Raheja}

Department of Anatomy, Dr Baba Saheb Ambedkar Medical College and Hospital, Rohini, Delhi, India
Correspondence: Suchismita Sarkar B-8, Sai Apartments, Sector-13, Rohini, Delhi, I 10085 , India

Tel +9l-7678642842

Email dr.suchi02@gmail.com
Purpose: The application of blended learning approach improves student engagement, active learning and achievement of higher order analytical thinking. Despite that there is still no clear proof that use of computer assisted learning is better than traditional teaching in human anatomy. In this study, a model of collaborative learning strategy is applied, using both online and face-to-face instruction delivery, for the Phase I medical students. The study aimed to innovate a model of blended learning in delivery of gross anatomy lectures and determine the effectiveness of this strategy in comparison to traditional classroom teaching by student's perception analysis.

Methods: Students were provided with PowerPoint lectures, clinical video of patient cases, and lecture summary handouts before the interactive face-to-face lecture session. Learner satisfaction survey was done to validate the student's perception.

Results: The students' participation in the survey was $90.4 \%$, with the mean of students' responses on the survey scale was $4.10 \pm 0.94$ (standard deviation). Highest agreement was $83.1 \%$ on the effectiveness of online resources. Students gave minimum agreement of $54.9 \%$ about the time allotted for the online materials. Thematic analysis of the perception of student feedback provided with many positive outcomes for this approach.

Conclusion: We propose that blended learning is a process that helps in enhancing student involvement and participation, motivation for self-directed learning and promotes deeper learning of educational outcomes.

Keywords: blended learning, anatomy, student engagement, online, interactive face to face

\section{Introduction}

Didactic lectures are instructional strategies used to deliver content to a large group audience. Integration of topics and contextual understanding has to occur. Retention of contextual information in long-term memory (deeper learning) of the students is questionable in a large group scenario with only passive knowledge delivery. ${ }^{1}$ Didactic lecture format is the less preferred way of learning as it delivers passive transfer of information, restricts the learner's attention span, and may affect the declarative/explicit memory formation. It is argued, to aid in the learning process that teachers can introduce variety in presentation and allow the learners to participate in question and answer (Q\&A) sessions intermittently.,

Modern medical colleges have to make a paradigm shift from informing students to involving them, which subserves the focus along the SPICES spectrum from teacher-centered to student-centered approach. ${ }^{1}$ Student learning enhances 
with active participation rather than as passive recipients of the information. Teacher-student interaction always helps to analyze, integrate, evaluate critically, and apply knowledge to correlate medical problems, which eventually helps develop clinical reasoning. To promote the students' active learning, the teacher must create opportunities within and outside the classroom. ${ }^{3-5}$ These opportunities involving active learning benefit the learner in developing the meaning of given information to understand better what needs to be learned.

Collaborative efforts by the students for learning develop self-directed learning activities such as completing a segment of the topic before the actual session, and subsequently, brainstorming and problem-solving during the lecture time. This intent to collaborate and actively engage the students in the learning process paved the way for using blended learning strategies to deliver information-dense lectures. Blended learning is technology/media integrated delivery of information with conventional faceto-face classroom activities. ${ }^{6}$ The variety of approaches for blending face-to-face class time with technology-enhanced learning include replacement or supplementation of lectures with recordings, the use of pre-class videos, online assessments, e-portfolios, wikis or online tutorials, and social media platforms. Sharing the advantage of both online and face-to-face classes, a well-planned yet flexible blended learning model can develop a student-centered collaborative learning experience.

Several authors have already proposed different blended learning methods to promote student engagement and enhancement of the active learning process. ${ }^{7,8}$

Traditional anatomy lecture theatre education can be complemented by innovating the blend of face-to-face and online classes to improve the retention of information and contextual learning. This initiative is in parlance with the recent launch of a new competency-based curriculum by the National Medical Commission (erstwhile Medical Council of India), to promote self-directed lifelong learners. It also advocates reducing the burden of the large group session. The apex authority has strongly proposed an outcome-based approach to health professions education by using information and technology to improve students' learning. ${ }^{9}$ Blended learning approach encompasses the core principles of competency-based medical education.

Few studies recently have introduced blended learning to anatomical sciences education, with fewer so to medical education of MBBS undergraduates. ${ }^{10,11}$ Therefore, the authors in the current study aimed at using a blended learning approach to the large group teaching of core competencies of the head, face and neck (gross anatomy) to the first year (preclinical) undergraduate medical students.

\section{Materials and Methods}

The project was reviewed and approved by the Institutional Ethics committee of Dr Baba Saheb Ambedkar Medical College, Delhi, India. All students were informed about voluntary participation in the study. The non-participation and the feedback of the participants would not have any ramifications on their course outcome. Informed consent was obtained from students before the collection of feedback data. The design is a cross-sectional descriptive study with the following research question "How satisfied are the students with the implementation of blended learning in anatomy large group session?"

\section{Course Structure}

The gross anatomy module Head, Face, and Neck was delivered to 125 students of Phase I of MBBS course, for 6 weeks. A blended learning approach was consistently used for the entire module. The other modules for anatomy comprised traditional lectures. During the course, the students were given an introductory class that outlined the modification in the traditional large group session. There were no significant changes to the small group tutorials and practical sessions during this module.

\section{Topic Format}

Each topic in this module included 2-3 hours of large group teaching sessions. Every topic was diligently prepared for months before the beginning of the session. All the topics in this module were covered under three subheadings (Figure 1).

(a) Before the large group session - Three days before beginning each topic, the students were given a lecture compiled handouts (printed and pdf versions), reference books to be read before the session, and a PowerPoint presentation.

(b) During the large group session - Fifty minutes of the lecture time was further divided into:

1. First 10 minutes - Probing for the muddiest points of the pre-session preparation (Interactive)

2. Second 15-20 minutes - Discussion of the critical concepts of the topic

3. Third 10-15 minutes - Interactive $Q$ and A session and feedback 


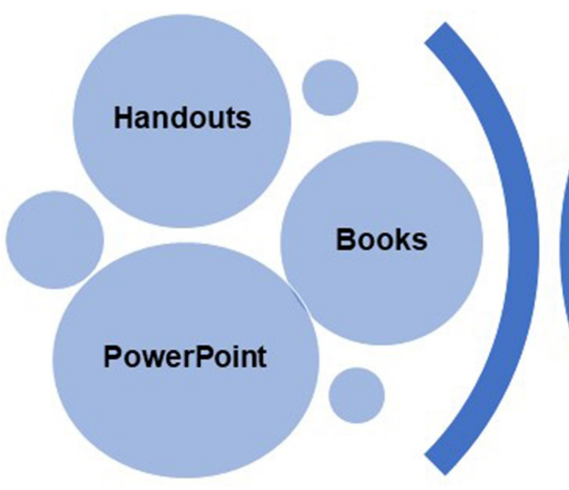

Before the large group session

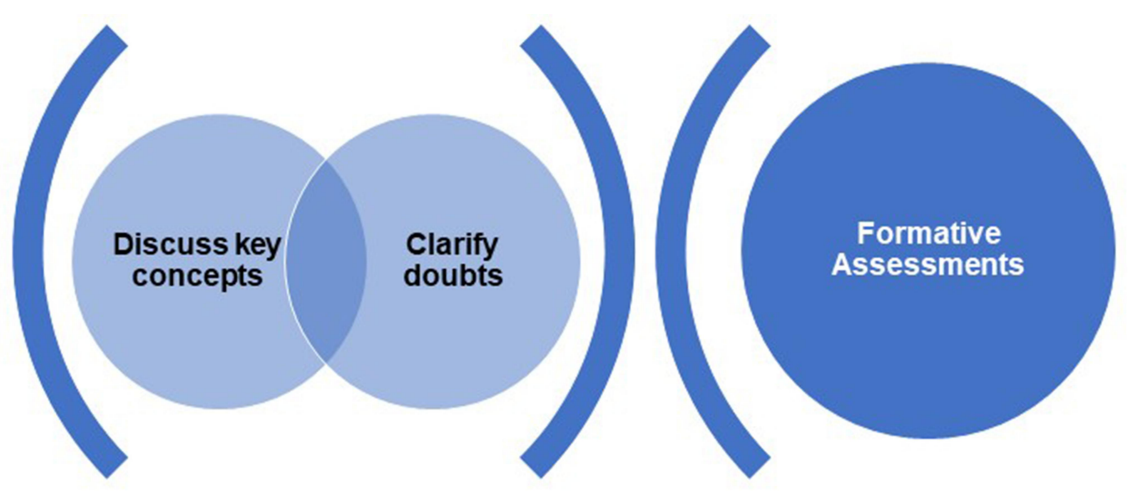

During the large group session

After large group session

Figure I Phased delivery of the blended learning approach for each topic in the head, face and neck anatomy module.

4. Last 10 minutes - Reflections on the process

(c) After the large group session - The students revised and reflected on the topic again at home/hostels after the session. This was followed by a formative assessment (FA) using MCQ-based questions administered through google forms. The FA was given weekly, every Thursday, containing questions that were covered in the previous week. According to Bloom's taxonomy, the question papers were blueprinted in such a way that $60-70 \%$ were application and analysis questions, and $30-40 \%$ were recall and understanding.

\section{Learner Satisfaction Survey}

At the end of the module, a three-sectioned learner satisfaction survey received integrative feedback on the blended learning approach's whole experience. Section 1 comprised the demographic data. Section 2 consisted of the 13 question survey analyzing the student's perspectives on the efficacy of various blended learning approaches. Feedback and comments on improving such endeavors were taken on in section 3 . All the sections were administered on google forms.

Validity is defined as the degree to which evidence and theory support the interpretations of test scores entailed by the proposed uses of tests. ${ }^{12}$ Emerging paradigms on "construct validity," ie, the degree to which a score can be interpreted as representing the intended underlying construct, has gained momentum. ${ }^{12,13}$ Hence, the educational assessment results have meaning (validity) only in the context of the construct they purport to assess. ${ }^{12-14}$ The learner satisfaction survey questionnaire was framed for the study with this concept of construct validity. The two experts reviewed the survey to check for clarity of purpose and address the concerned issues. The reliability coefficient Cronbach's alpha for the learner satisfaction survey was 0.902 .

The quantitative part of the data was analyzed using SPSS software version 26.0. The students' perception of satisfaction was analysed by calculating the percentages of strongly agree and agree on the Likert scale analysis. The means and standard deviation of all the items on the Likert scale were tabulated. The qualitative part was interpreted, compiled, and referenced by two experts using constant comparative analysis of grounded theories in reflective writing. The thematic analysis, thus done, was then tabulated and organized according to the most common themes presented.

\section{Results}

The blended learning model was applied to 125 students in Phase I of the MBBS course in a government medical college in northern India. Participation in the survey on blended learning survey was voluntary. We received 113 responses out of 125 students who were administered the questionnaire, making the participation percentage $90.4 \%$. Attendance throughout the module during the face-to-face interaction was on an average of $87.2 \%$.

\section{Quantitative Observations}

Analysis of the Learner Satisfaction Survey

Section 1 of the survey contained the students' demographic details like name, roll number, and email id.

Section 2 of the survey contained the 13 items Likert scale questionnaire with randomly assorted questions for 
every student. These questions were broadly categorized the student's perception into two:

1. Improvement of the learning process by blended learning instead of traditional face-to- face lectures - contained six items (Item numbers 1, 2, 3, $4,8,13)$.

2. Organization of the blended learning model delivery system - contained seven items (Item numbers $5,6,7,9,10,11,12)$.

Figure 2 summarizes the bar chart representation of four (Figure 2A-D) of the response items involved in improving the learning as felt by the students. The average of the responses in category 1 was 4.09. Figure 3 shows the bar chart representations of four (Figure 3A-D) of the responses in the items involved in how well the blended classroom model was delivered. The average of the responses in category 2 was 4.11 .

Table 1 shows the questionnaire items in section 2 of the learner satisfaction survey with the mean and standard deviation of each item's student responses. The higher percentage of responses in the strongly agree category (equivalent to Likert scale 5 scores) and agree (equivalent to Likert scale 4 scores) shows the Blended learning approach's acceptability.

\section{Qualitative Observations}

The thematic analysis was done for the students' qualitative feedback about the blended learning model of teaching and brought out many positive themes. The representative summary of the positive themes is given in Table 2.

Student's perceptions also brought out a few improvement themes from the model. They are summarized as follows:

- More time for face-to-face discussion should be there.

- More clinical patient videos should be included.

- Use more animated videos to explain the core topics.

- Reduce the information density of the subject.

- Instead of material given before each session, it could be given at once before starting the module to fathom the depth of the effort to be made in this module.

- Instead of weekly formative assessments, quick tests after every face-to-face session.
A
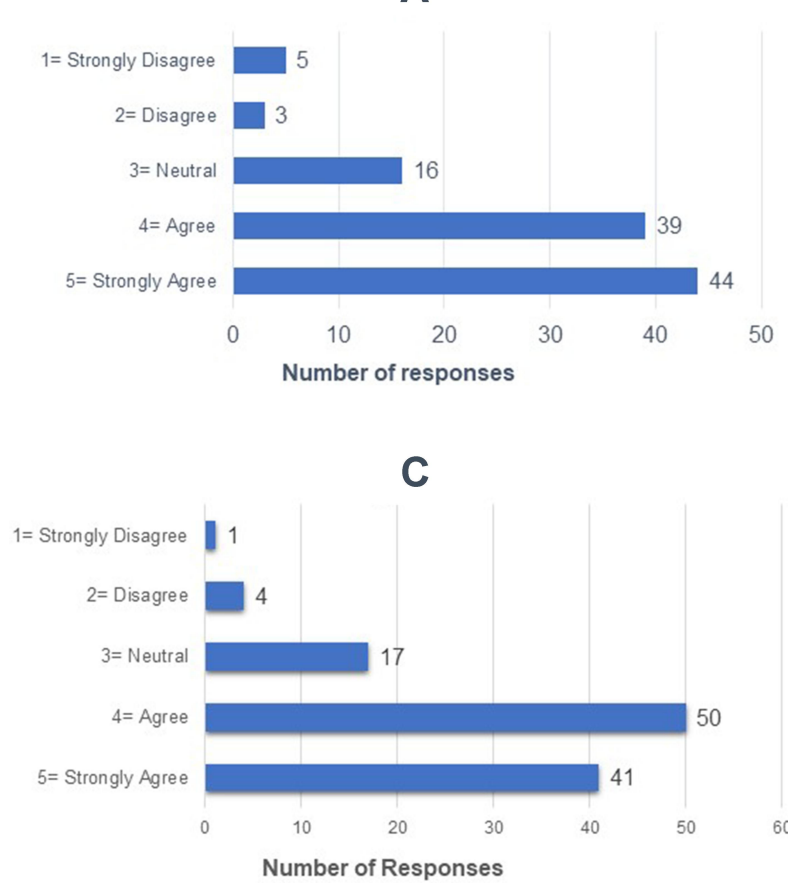

B
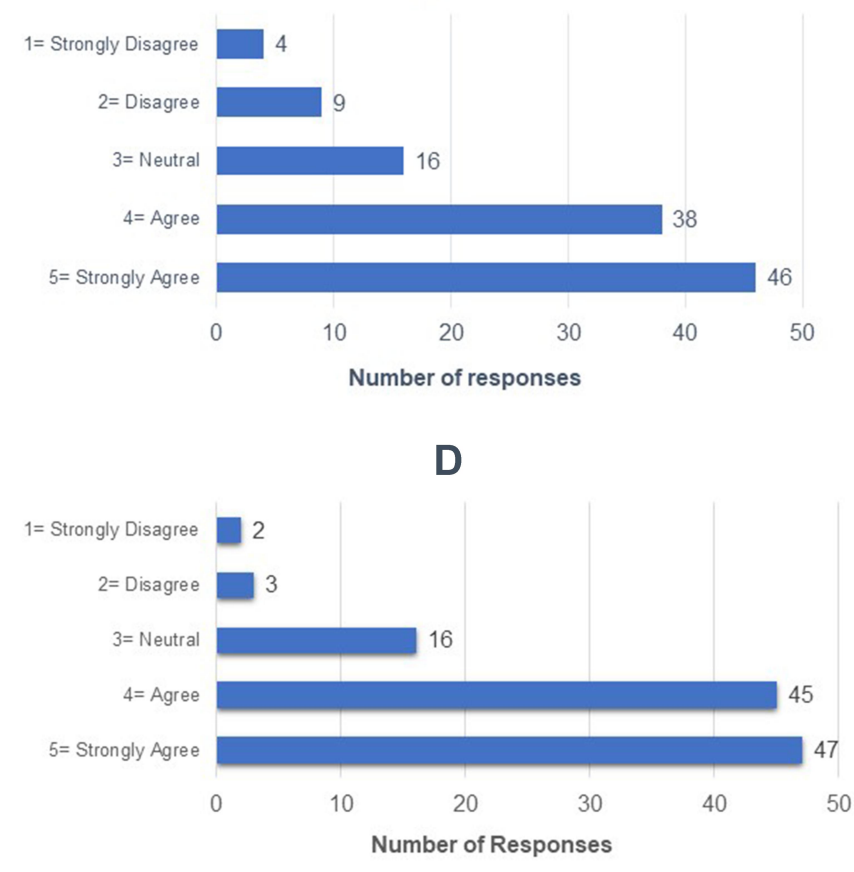

Figure 2 Bar representation of the student responses on a likert scale rating of four items in category I (Improvement of the learning process) of the learner satisfaction survey. (A) I prefer BL over traditional lectures. (B) My attention and engagement in class was enhanced by BL (C) BL approach enhanced my self-directed learning ability. (D) Felt confident to interact in the face-to-face sessions. 

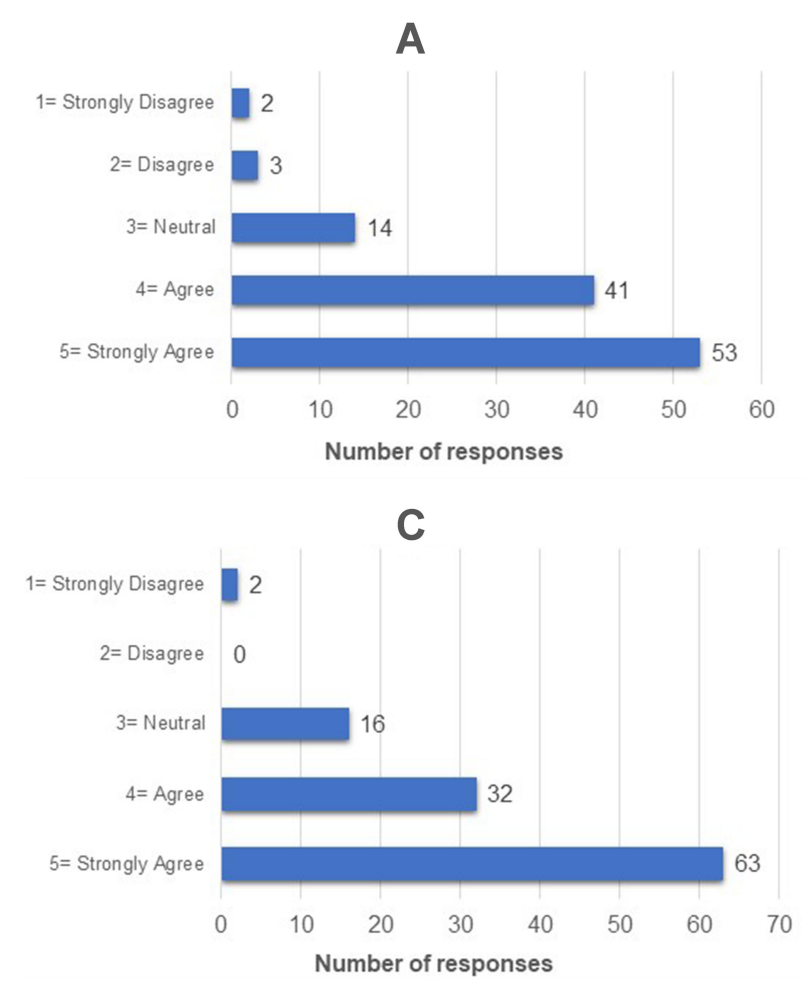

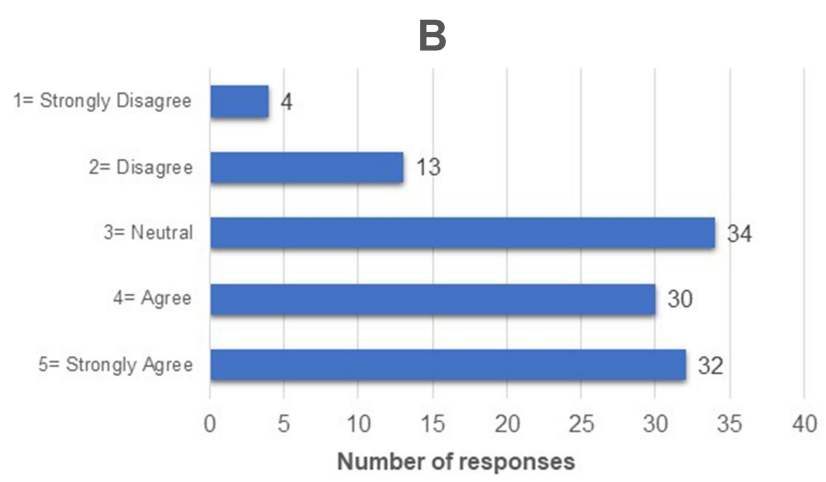

D

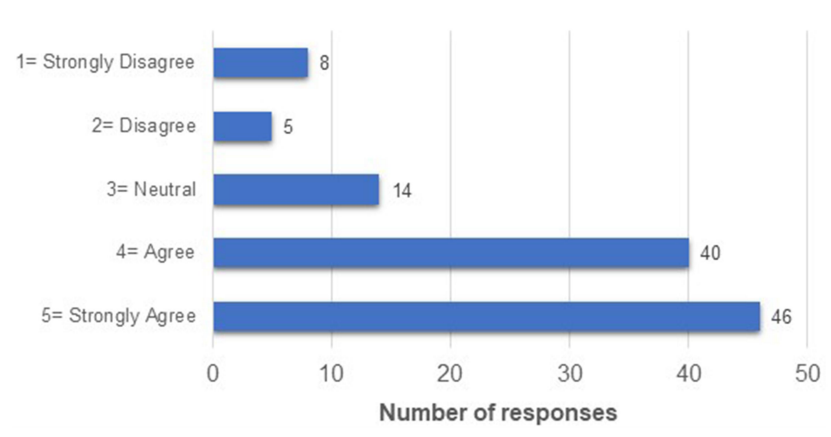

Figure 3 Bar representation of the student responses on a likert scale rating of four items in category 2 (Organization of the blended learning model) of the learner satisfaction survey. (A) Pre-lecture PowerPoint presentations helped in understanding the topics better. (B) Fairly adequate time was available for the Pre-lecture online materials. (C) Patient videos for early clinical exposure sessions provided contextual understanding of the core topic. (D) Formative assessments motivated us to complete the topics in the module.

- To make the module a permanent method of lecture delivery for anatomy and other preclinical subjects.

- There should be the inclusion of subjective aspects (like short answer questions) in the formative assessment instead of only MCQs.

\section{Discussion}

The present study incorporated a blended learning model for teaching Head, face, and Neck module in gross anatomy to the Phase I MBBS students. The lecture session began with interactive teaching with the students to

Table I Mean and Standard Deviation of Students Responses in Section 2 of the Learner Satisfaction Survey Questionnaire on a 5 Point Likert Scale Ranging from Strongly Disagree to Strongly Agree (BL - Blended Learning)

\begin{tabular}{|c|c|c|c|c|}
\hline $\begin{array}{l}\text { Item } \\
\text { Number }\end{array}$ & Questionnaire Items & Mean & $\begin{array}{l}\text { Standard } \\
\text { Deviation }\end{array}$ & $\begin{array}{c}\text { Percentage of } \\
\text { Students Who } \\
\text { Strongly Agree and } \\
\text { Agree(\%) }\end{array}$ \\
\hline 1 & I prefer BL over traditional lectures for anatomy & 4.09 & 1.05 & 77.9 \\
\hline 2 & BL approach enhanced my self-directed learning ability & 4.12 & 0.84 & 80.5 \\
\hline 3 & BL was an effective motivating learning process & 4.02 & 0.89 & 75.2 \\
\hline 4 & $\mathrm{BL}$ promotes and thinking and practice ability & 4.11 & 0.82 & 75.2 \\
\hline 5 & BL sessions were well organised & 4.17 & 0.84 & 82.3 \\
\hline 6 & Facilitator provided sufficient opportunities for discussions & 4.15 & 0.82 & 78.8 \\
\hline 7 & Pre-lecture PowerPoint presentations helped in understanding the topics better & 4.24 & 0.90 & 83.1 \\
\hline 8 & My attention and engagement in class was enhanced by $\mathrm{BL}$ & 4.00 & 1.09 & 74.3 \\
\hline 9 & Fairly adequate time was available for the Pre-lecture online materials & 3.64 & 1.11 & 54.9 \\
\hline 10 & Printed/Softcopy handouts of topic were concise, relevant and helped in understanding & 4.21 & 0.90 & 83.2 \\
\hline 11 & Patient videos for early clinical exposure sessions provided contextual understanding of the core topic & 4.36 & 0.85 & 84.1 \\
\hline 12 & Formative assessments motivated us to complete the topics in the module. & 3.98 & 1.15 & 76.1 \\
\hline 13 & Felt confident to answer questions in the face to face sessions & 4.17 & 0.89 & 81.4 \\
\hline
\end{tabular}


Table 2 Thematic Analysis of Student Feedback on Blended Learning Model

\begin{tabular}{|c|c|}
\hline Themes Identified & Representative Student Comments \\
\hline $\begin{array}{l}\text { Promote understanding and } \\
\text { deeper learning }\end{array}$ & $\begin{array}{l}\text { - "You get revision in class which makes it easy to memorize things." } \\
\text { - "Could relate to what has been taught in class, and repeated revisions." } \\
\text { - "That I read the topic and remembered } 70 \% \text { during the class." } \\
\text { - "It helps me to maintain my ideas and notes well about the related topic and better understanding." } \\
\text { - "Having an assurance that the content being taught is provided so the focus shifts to understanding the } \\
\text { concept than memorising/noting down." }\end{array}$ \\
\hline $\begin{array}{l}\text { Encouraged self-directed } \\
\text { learning }\end{array}$ & $\begin{array}{l}\text { - "The involvement and the control over what I am learning in a way that's best for me." } \\
\text { - "At last bunch of relevant sources in your hand. It is really helpful for revision." }\end{array}$ \\
\hline Positively motivated students & $\begin{array}{l}\text { - "Know what to read in an organised way with a prerequisite knowledge." } \\
\text { - "Easy to understand topics." } \\
\text { - "I can complete the topic on time, which motivated me to stick to the schedule." }\end{array}$ \\
\hline Confident to interact in class & $\begin{array}{l}\text { - "It made me feel confident in that topic." } \\
\text { - "I felt confident to solve problems in class after going through online PPTs and handouts." } \\
\text { - "It increases our confidence by improving our learning in lectures." }\end{array}$ \\
\hline Flexibility of timing & $\begin{array}{l}\text { - "Providing adequate material beforehand." } \\
\text { - "Now I know what topics and the extent to read before lecture." } \\
\text { - "It gave us more time to study." } \\
\text { - "I can see online PPTs as many times as I want." }\end{array}$ \\
\hline Feedback driving learning & $\begin{array}{l}\text { - "Able to relate in classroom. Weekly assessment is best." } \\
\text { - "Grading of the assignment provided was helpful." }\end{array}$ \\
\hline
\end{tabular}

enquire about their understanding of the online materials and find the muddiest points in their learning efforts. The face-to-face session then progressed to clarify the concepts and reinforce the core competencies for the next 15-20 minutes. According to the previous literature, this time limit was kept, which shows that the student's attention span in an hour of lecture remained only for 15-20 minutes. ${ }^{1}$ This was followed by discussing the most critical questions from the topic and a collaborative effort to answer them. During this approach, authors have found students to be more encouraged and engaged, as agreed by $74.3 \%$ of them. Collaborative thinking in class helped the students to analyze the anatomical context behind clinical problems critically. It promoted contextual learning, which forms the basis for deeper learning and the development of declarative memory. The session ended with the positive encouragement of students' efforts to learn and prepare before the class and reflect on the process for the particular topic. Authors were provided with valuable insights into the successful implementation of the blended learning model. The students became responsible collaborators in their learning process and looked forward to more handouts on topics that integrated systems relevant to those regions. For example, all the arterial supply, lymphatic drainage, venous drainage to the region compiled in a flowchart form for strategic learning. We improvised from time to time, with frequent supplementations to the online course content, which the students accepted very well.

The weekly formative assessment motivated the students to revise the topics and prepare in advance for them. It was appreciated as an excellent motivational tool by the students $(75.2 \%$ agreed) to be regular in studies and minimized the lag that develops during the longer duration, information-dense core anatomy sessions like head, face, and neck.

With the recent launch of the early clinical exposure in the new curriculum, patient videos for clinical conditions provided helpful learning context. ${ }^{11}$ The video was provided along with online materials before the lecture, which enriched the discussion level during the face-to-face sessions. These were the "Aha moments" enjoyed by the students, as agreed by $84.1 \%$.

Few aspects of the online materials (handouts, clinical videos) were unique to this study population and have not been reported before. This model's popularity has also been accepted by the other higher education and 
professional courses. ${ }^{15-17}$ One of the prominent themes emerging from this teaching-learning methodology format was more retention of a greater percentage of the content. It also increased the level of understanding among the students from unconscious incompetence to conscious competence. Few studies with blended learning for nurses' education also revealed similar observations. ${ }^{18-20}$

Self-directed learning, which is a cornerstone in the adult learning process, has to be inculcated. Students admitted in Phase I of MBBS are used to the teacher-centered pedagogy during their secondary and senior secondary schools. Several challenges are faced when strategies like self-directed learning are used to implement a competency-based curriculum to achieve better student learning outcomes. The authors used the blended learning model to inculcate the self-directed learning ability (agreed upon by $80.5 \%$ of students). It was seen that the students found it self-motivating as well (75.2\%). A study on the efficacy of self-directed programs using blended learning has been done in nurses' education. ${ }^{21}$

In our study, $81.4 \%$ of students felt they are more aware of the lecture's progress, which helped build confidence to communicate and deliberate during the sessions. Students were more comfortable and confident to connect with the facilitator during the face-to-face interaction. Beforehand, providing study materials and presentations has proved productive to enhance the classroom's interactivity, which corroborated with other studies. ${ }^{22-24}$ The Q and A technique used in the face-to-face sessions to enhance engagement and increase student satisfaction and participation in discussions. The effectiveness of classroom assessments and formative feedback assessments has been established time and again. ${ }^{25,26}$

Studies show that established resource management regulation strategies, time and study environment, and effort regulation directly affected students' examination scores. ${ }^{27,28}$ We also observed that the quality of teaching (agreed by $78.8 \%$ students) and online resources management (agreed by $83.1 \%$ and $83.2 \%$ students, for PowerPoint and lecture handouts, respectively) does influence the outcome of the blended learning model agreed upon by other studies. ${ }^{29,30}$

On the suggestions given by the students, the authors propose the following strategies which could be incorporated and further studied:

1. Delimiting few lectures - Once in a week extending beyond the one-hour limit, which gives a scope of better Q \& A sessions and clarification of doubts.
2. Conducting few un-announced assessments in between the lectures would assess student's progression of learning in a better way and motivate them to be regular.

3. Personal mentoring/coaching of students - The students who lagged in either following up the schedule or participating in the class discussion should be counselled from the beginning of the module.

4. Interactive sessions could be made better by using online quizzes using gaming software to improve student enthusiasm and participation.

The institutional policy of universal instruction delivery prevented us from dividing the students into cases and control groups. So we could not compare the results of traditional to one study group and blended learning to another study group, to establish a comparative analytical study.

\section{Conclusions}

To summarize, some of the best practices to support proper conduction of blended learning is:

- Introducing the process at the beginning

- Strict timed delivery of online materials

- Accountability for online activities

- Constructive feedback on student preparation

- Peer reviewing of online material

- User-friendly technology

Our blended learning approach could be an effective model for large group teaching sessions for the medical undergraduate curriculum.

\section{Acknowledgments}

We acknowledge all our students who participated in the study, our ex-head of department for her constructive feedback and support and colleagues who gave constant encouragement and motivation during the process of implementation of the study.

\section{Disclosure}

The authors report no conflicts of interest in this work.

\section{References}

1. Samarasekera DD, Gwee MCE, Long A, Lock B. Lectures and large groups. In: Swanwick T, Forrest K, O’Brien BC, editors. Understanding Medical Education: Evidence, Theory and Practice. 3rd ed. John Wiley and Sons Ltd; 2019:113-121. 
2. Stuart J, Rutherford RJ. Medical student concentration during lectures. Lancet. 1978;2(8088):514-516. PMID: 79879. doi:10.1016/s0140-6736(78)92233-x

3. Meyers C, Jones TB. Promoting Active Learning Strategies for the College Classroom. San Francisco, CA: Jossey-Bass Inc; 1993.

4. Chuang Y-T. Increasing learning motivation and student engagement through the technology-supported learning environment. Creative Edu. 2014;5:1969-1978. doi:10.4236/ce.2014.523221

5. Gresham CL, Philip JR. Problem-based learning in clinical medicine. Teach Learn Med. 1996;8:111-115. doi:10.1080/10401339609539776

6. Picciano A. Blended learning: implications for growth and access. JALN. 2009;10(3):95-102.

7. Herbert C, Velan GM, Pryor WM, Kumar RK. A model for the use of blended learning in large group teaching sessions. BMC Med Educ. 2017;17(1):197. PMID: 29121908; PMCID: PMC5680783. doi:10.1186/s12909-017-1057-2

8. Francis R, Shannon SJ. Engaging with blended learning to improve students' learning outcomes. EJEE. 2013;38(4):359-369.

9. Board of Governors, MCI. Amendment to the regulations to the graduate medical education. E-gazette of India; 2019. 59-99. Available from: https://www.nmc.org.in/ActivitiWebClient/open/getDocument?path=/ Documents/Public/Portal/Gazette/GME-06.11.2019.pdf

10. Khalil MK, Abdel Meguid EM, Elkhider IA. Teaching of anatomical sciences: a blended learning approach. Clin Anat. 2018;31 (3):323-329. PMID: 29352730. doi:10.1002/ca.23052

11. Green RA, Whitburn LY, Zacharias A, Byrne G, Hughes DL. The relationship between student engagement with online content and achievement in a blended learning anatomy course. Anat Sci Educ. 2018;11(5):471-477. PMID: 29236359. doi:10.1002/ase.1761

12. Cook DA, Beckman TJ. Current concepts in validity and reliability for psychometric instruments: theory and application. Am J Med. 2006;119 (2):166.e7-16. PMID: 16443422. doi:10.1016/j.amjmed.2005.10.036

13. Downing SM. Validity: on meaningful interpretation of assessment data. Med Educ. 2003;37(9):830-837. PMID: 14506816. doi:10.1046/j.1365-2923.2003.01594.x

14. Vyas R, Tharion E, Sathishkumar S. Improving the effectiveness of physiology record books as a learning tool for first-year medical students in India. Adv Physiol Educ. 2009;33(4):329-334. PMID: 19948684. doi:10.1152/advan.00050.2009

15. Kabassi K, Dragonas I, Ntouzevits A, Pomonis T, Papastathopoulos G, Vozaitis Y. Evaluating a learning management system for blended learning in Greek higher education. Springerplus. 2016;5:101. PMID: 26877899; PMCID: PMC4735041. doi:10.1186/ s40064-016-1705-8

16. Keržič D, Tomaževič N, Aristovnik A, Umek L. Exploring critical factors of the perceived usefulness of blended learning for higher education students. PLoS One. 2019;14(11):e0223767. PMID: 31751345; PMCID: PMC6872162. doi:10.1371/journal.pone.0 223767

17. Lazar IM, Panisoara G, Panisoara IO. Digital technology adoption scale in the blended learning context in higher education: development, validation and testing of a specific tool. PLoS One. 2020;15(7): e0235957. PMID: 32649691; PMCID: PMC7351189. doi:10.1371/ journal.pone.0235957

Advances in Medical Education and Practice

\section{Publish your work in this journal}

Advances in Medical Education and Practice is an international, peerreviewed, open access journal that aims to present and publish research on Medical Education covering medical, dental, nursing and allied health care professional education. The journal covers undergraduate education, postgraduate training and continuing medical education
18. Shang F, Liu CY. Blended learning in medical physiology improves nursing students' study efficiency. Adv Physiol Educ. 2018;42 (4):711-717. PMID: 30431319. doi:10.1152/advan.00021.2018

19. Sáiz-Manzanares MC, Escolar-Llamazares MC, Arnaiz González Á. Effectiveness of blended learning in nursing education. Int $J$ Environ Res Public Health. 2020;17(5):1589. PMID: 32121514; PMCID: PMC7084479 doi:10.3390/ijerph17051589.

20. Shimizu I, Nakazawa H, Sato Y, Wolfhagen IHAP, Könings KD. Does blended problem-based learning make Asian medical students active learners?: a prospective comparative study. BMC Med Educ. 2019;19(1):147. PMID: 31092243; PMCID: PMC6521359. doi:10.1186/s12909-019-1575-1

21. Noh GO, Kim DH. Effectiveness of a self-directed learning program using blended coaching among nursing students in clinical practice: a quasi-experimental research design. BMC Med Educ. 2019;19 (1):225. PMID: 31234843; PMCID: PMC6591891. doi:10.1186/ s12909-019-1672-1

22. Moon H, Hyun HS. Nursing students' knowledge, attitude, selfefficacy in blended learning of cardiopulmonary resuscitation: a randomized controlled trial. BMC Med Educ. 2019;19(1):414. PMID: 31706315; PMCID: PMC6842519. doi:10.1186/s12909-0191848-8

23. Hussain M, Zhu W, Zhang W, Abidi SMR. Student engagement predictions in an e-learning system and their impact on student course assessment scores. Comput Intell Neurosci. 2018:6347186. PMID: 30369946; PMCID: PMC6189675. doi:10.1155/2018/6347186

24. Halasa S, Abusalim N, Rayyan M, et al. Comparing student achievement in traditional learning with a combination of blended and flipped learning. Nurs Open. 2020;7(4):1129-1138. PMID: 32587732; PMCID: PMC7308688. doi:10.1002/nop2.492

25. Lutze-Mann L, Kumar RK. The formative assessment lecture: enhancing student engagement. Med Educ. 2013;47(5):526-527. . PMID: 23574083. doi:10.1111/medu. 12162

26. Hudson JN, Bristow DR. Formative assessment can be fun as well as educational. Adv Physiol Educ. 2006;30(1):33-37. PMID: 16481607. doi:10.1152/advan.00040.2005

27. Kassab SE, Al-Shafei AI, Salem AH, Otoom S. Relationships between the quality of blended learning experience, self-regulated learning, and academic achievement of medical students: a path analysis. Adv Med Educ Pract. 2015;6:27-34. PMID: 25610011; PMCID: PMC4293215. doi:10.2147/AMEP.S75830

28. Margolis AR, Porter AL, Pitterle ME. Best practices for use of blended learning. Am J Pharm Educ. 2017;81(3):49. PMID: 28496269; PMCID: PMC5423065. doi:10.5688/ajpe81349

29. Shah S, Cox AG, Zdanowicz MM. Student perceptions of the use of pre-recorded lecture modules and class exercises in a molecular biology course. Curr Pharm Teach Learn. 2013;5(6):651-658. (). doi:10.1016/j.cptl.2013.07.011

30. Moskal PD, Cavanagh TB. Scaling blended learning evaluation beyond the university. In: Picciano AG, Dziuban CD, Graham CR, editors. Blended Learning: Research Perspectives. Vol. 2. London, UK: Routledge; 2014:34-51. including emerging trends and innovative models linking education, research, and health care services. The manuscript management system is completely online and includes a very quick and fair peer-review system. Visit http://www.dovepress.com/testimonials.php to read real quotes from published authors.

\section{Dovepress}

